\title{
Effect of oxygen and structural properties on the electrical conductivity of powders of nanostructured carbon materials
}

\author{
S. Pérez-Rodríguez*, D. Torres, M. J. Lázaro* \\ Instituto de Carboquímica (CSIC), Miguel Luesma Castán 4, 50018 Zaragoza, Spain. \\ *Corresponding author: \\ M.J. Lázaro: Tel number: 0034976733977. E-mail address: mlazaro@icb.csic.es. \\ S. Pérez-Rodríguez: Tel number: 0034976733977. E-mail address: sperez@icb.csic.es.
}




\begin{abstract}
This work reports a study of the electrical conductivity under compression of nanostructured carbon powders with different physicochemical properties (texture, chemical-surface and morphology): a commercial carbon black (Vulcan XC-72R) and synthesized ordered mesoporous carbon (OMC), carbon nanocoils (CNC) and carbon nanofibers (CNF). The electrical conductivity was determined from the sample resistance under compaction (from 0.5 to $140 \mathrm{MPa}$ ) using the four-probe technique. A comparison of intrinsic and grain electrical conductivities (calculated according to the percolation theory and the general effective media approximation) was performed. Additionally, samples were subjected to chemical oxidation or graphitization treatments to evaluate the effect of oxygen content and structural properties on the electrical conductivity. In spite of the physicochemical differences of carbon materials, an exponential decrease of the electrical conductivity with the oxygen amount was stated. Finally, thermal treatment of $\mathrm{OMC}$ at $1500{ }^{\circ} \mathrm{C}$ led to a surprising increase in its conductivity due to the graphitization of the amorphous carbon structure of the original material and the oxygen removal.
\end{abstract}

Keywords: nanostructured carbon powders; electrical conductivity under compression; intrinsic electrical conductivity; graphitization; oxygen functionalization. 


\section{Introduction}

In the last decade, the study of filler materials that impart electrical conductivity in polymer composites has been implemented in order to be used for antistatic electricity, electromagnetic shielding, electronic components or electrodes in energy conversion electrochemical devices [1-12]. Among these fillers, nanostructured carbon materials exhibit clear advantages over the use of metal powders or fibers as filler, according to their high electrical and thermal conductivities, potentially low production cost, oxidation stability or low density [5]. The irruption of carbon nanotubes (CNT) in 1999 in this field [13], that was already explored with carbon blacks [14-16], graphite [17] and carbon fibres [18], has brought up the use of other carbon materials whose basic structural unit is also graphene such as carbon nanofibers (CNF) $[19,20]$, fullerenes $[21,22]$ or $2 \mathrm{D}$ graphene-based materials [23]. Carbon nanofilaments, and especially CNT, exhibit high electrical conductivity due to their graphite-like structure, low mass density and high aspect ratio, which allows both using them as a conductive filler using a very low content and reducing the electrical percolation threshold to extremely low values [6, 13, 24-26]. In this regard, only graphene with a laminar morphology has obtained electrical percolation thresholds comparable to $\mathrm{CNT}[23,27]$ and outstanding electronic properties [28]: very high electron mobility even at room temperature $\left(10^{5} \mathrm{~cm}^{2} \mathrm{~V}^{-1} \mathrm{~s}^{-1}\right)$ [29], very high electrical conductivity $\left(10^{8} \mathrm{~S} \mathrm{~m}^{-1}\right)$ resisting current densities of $10^{8} \mathrm{~A} \mathrm{~cm}^{-2}[30,31]$, or ballistic transport at room temperature [28]. These unusual electronic properties are intrinsic to the graphene structure and they are due to the $\pi$-orbitals in which each carbon atom contributes an electron to form a cloud of delocalized electrons.

Electrical conductivity of carbon nanofilaments is related to the electronic structure (e.g. chirality in case of single-wall carbon nanotubes (SWCNT)) [32], contact effects and size of the graphene layers [33], being its magnitude of orders very different 
depending on whether it is an isolated nanofilament [34-39] or a bulk system made by hundreds of them [33, 40-43]. Electrical conductivities as high as $2 \cdot 10^{7}$ and $2 \cdot 10^{5} \mathrm{~S} \mathrm{~m}^{-}$ ${ }^{1}$ for isolated single (SWCNT) and multiwall carbon nanotubes (MWCNT), respectively, were measured [35-37]. In addition to this high conductivity, other exceptional properties, such as electron ballistic transport or superconductivity, have been demonstrated for carbon nanotubes $[38,44,45]$. On the other hand, the so-called bulk electrical conductivity (or powder electrical conductivity) of carbon nanofilaments is not easy to measure and it depends on their compaction degree. Marinho et al. [41] reported an electrical conductivity about $540 \mathrm{~S} \mathrm{~m}^{-1}$ at $5 \mathrm{MPa}$ of pressure for a MWCNT powder. In the case of CNF, electrical conductivity measurements of an isolated nanofiber have not been reported; however, bulk conductivity has been found to be in the range 20-3000 S m$~^{-1}$ (depending on the measurement conditions), which is comparable to that shown by MWCNT [33, 40, 46, 47]. According to the production cost, host matrix features or functionalization possibilities, the use of other carbon materials cannot be discarded. Thus, in addition to MWCNT [41-43] and CNF [33, 40], the bulk electrical conductivity under compaction of a wide variety of carbon materials has been measured: synthetic and natural graphite [41-43, 48-52], petroleum and isotropic coke [49, 51], activated carbon $[49,51]$, carbon black [41, 42, 49, 51, 53-55], ordered mesoporous materials [56] and graphene, graphene oxide (GO) and reduced graphene oxide (rGO) $[41-43,57]$.

Besides to the aspect ratio or the particle shape, other parameters have influence on the electrical percolation threshold, such as the surface area, anisotropy, impurity content or surface functionalization, being also very influential in the interactions between particles and particles/matrix. Anisotropic conductivity has been determined in graphite with electrical conductivities around $10^{5}-10^{6}$ and $10^{2}-10^{4} \mathrm{~S} \mathrm{~m}^{-1}$ in parallel and 
perpendicular directions to graphene layers, respectively $[58,59]$, since delocalized $\pi$ electrons move mainly along the 2D network of $\mathrm{sp}^{2}$-carbon. In a graphite-like nanostructure carbon material, the electrical conductivity will depend on the connection and arrangement of the graphene stacks. As Sebastián et al. pointed out in [33], CNF show a semiconducting behaviour [60] as a result of the electrical conduction in the perpendicular direction to graphene layers $[58,61]$. At this point, a conductive carbon material containing highly conductive graphite stacks at the nanoscale may present a lower bulk (or apparent) electrical conductivity due to restrictive contributions, i.e. structural defects like vacancies or dislocations in the graphene layers, or those due to contacts at different scales (among crystal domains, particles and grains) [58, 62]. In compressed powders, the resulting electrical conductivity will be the result of a combination of the electrical conductivity of the individual particles, and other potentially modifiable parameters under compression, such as the contact degree among the particles or their packing [54]. Under pressure, the higher the number of contacts among particles, the higher the number of channels available for the transport of electric current.

In spite of hampering electronic conduction in a $\mathrm{sp}^{2}$ carbon network, oxygen functionalization is a useful tool to improve the homogeneity and interfacial bonding between the filler particles and the host polymer matrix when they are not initially compatible [27, 63]. Conversely, electrical conductivity of carbon-based fillers can be increased by deoxygenation. In this context, graphitization treatments proven to be highly effective, restoring the graphitic network of $\mathrm{sp}^{2}$ bonds [23, 64]. The influence of the surface chemistry on electrical conductivity of nanostructured carbon materials has already been addressed for compressed powders, including acid-oxidized CNF [40], carbon blacks with different $\mathrm{O}$ and $\mathrm{S}$ contents [53, 55], graphitized OMC [56] or rGO $[43,57]$. 
Although considerable research has been devoted to the study of the electrical conductivity of composites using carbon as filler [5-7, 9, 10, 13-17, 19, 20, 25], rather less attention has been paid to the bulk electrical conductivity of nanostructured carbon powders in isolation (without polymer matrix). On the other hand, there is a lack in existing literature of comparative studies about the electrical conductivity of carbon powders, especially using the same experimental device. Additionally, the electrical conductivity values are usually reported at a given applied pressure (apparent conductivity), which makes difficult a direct comparison of the results of different carbon materials and only few studies focus on the calculation of intrinsic conductivities, as it is addressed in this work.

This paper reports a comparative analysis of the electrical conductivity measurements of powders of different nanostructured carbon materials under compression (from 0.5 to $140 \mathrm{Mpa}$ ). Electrical conductivity was calculated from the sample resistance measurement under compaction using the four-probe technique. A commercial carbon black (Vulcan XC-72R) and synthesized carbons (CNF, ordered mesoporous carbon (OMC) and carbon nanocoils (CNC) $[65,66])$ were compared by relating their electrical conductivities and other physicochemical features, such as textural, chemical-surface, structural and morphological properties. In addition, Vulcan, $\mathrm{CNF}$ and $\mathrm{CNC}$ were chemically oxidized with concentrated nitric acid and OMC were subjected to a graphitization treatment in order to study the effect of the oxygen content and structural properties on the electrical conductivity. For the first time, a comparison of intrinsic and grain electrical conductivities of different powdered carbon nanomaterials is presented. It is worth noting that the intrinsic electrical conductivities of OMC and CNC have not been reported before in literature. 


\section{Experimental}

\subsection{Synthesis of nanostructured carbon materials}

The carbon black Vulcan XC-72R (supplied by Cabot) was used to establish a comparison with a commercial material. In addition, Vulcan was subjected to a strong oxidation treatment $\left(\mathrm{O}_{\mathrm{s}}\right)$ with concentrated nitric acid (65 wt. \%, Panreac) for $2 \mathrm{~h}$ at 120 ${ }^{\circ} \mathrm{C}$ to create oxygen functional groups on the carbon surface $[67,68]$. In this way, the effect of oxygen functionalization on the electronic conductivity was studied. The oxidized carbon was labelled as Vulcan-Os.

OMC were prepared by the nanocasting technique using a mesoporous silica (SBA-15) as template and a furan resin/acetone as carbon precursor [66]. In order to increase the crystalline degree and consequently, the electrical conductivity of synthesized OMC, the carbon material was subjected to a heat treatment under an Ar flow at $1500{ }^{\circ} \mathrm{C}$ for $1 \mathrm{~h}$ with a heating rate of $10^{\circ} \mathrm{C} / \mathrm{min}$ [56]. The graphitized carbon was denoted as OMC-g.

$\mathrm{CNF}$ were synthesized by methane decomposition at $700{ }^{\circ} \mathrm{C}$ on a $\mathrm{NiCuAl}_{2} \mathrm{O}_{3}$ (atomic ratio 78:6:16) catalyst [66]. After CNF synthesis, the metal particles were removed by means of two different oxidation treatments with concentrated nitric acid (65 wt. \%, Panreac) for $2 \mathrm{~h}$ at $25{ }^{\circ} \mathrm{C}$ (mild oxidation: $\mathrm{O}_{\mathrm{m}}$ ) or $120{ }^{\circ} \mathrm{C}$ (strong oxidation: $\mathrm{O}_{\mathrm{s}}$ ), resulting in the materials denoted as $\mathrm{CNF}-\mathrm{O}_{\mathrm{m}}$ and $\mathrm{CNF}-\mathrm{O}_{\mathrm{s}}$, respectively.

$\mathrm{CNC}$ were prepared by the catalytic graphitization method using $\mathrm{Ni}$ and $\mathrm{Co}$ nitrates as graphitization catalysts, a mixture of resorcinol and formaldehyde as the carbon precursor and silica sol to generate mesoporosity [66]. Obtained CNC were treated with concentrated nitric acid ( $65 \mathrm{wt} . \%$, Panreac) at $25{ }^{\circ} \mathrm{C}$ for $2 \mathrm{~h}$ for eliminating the metal content, obtaining the material labelled as $\mathrm{CNC}-\mathrm{O}_{\mathrm{m}}$. 
Besides to the removal of metal nanoparticles, the treatments with nitric acid result in the introduction of oxygen functionalities on CNF and CNC [65].

\subsection{Physicochemical characterization}

The morphology of nanostructured carbons was studied by scanning electron microscopy (SEM) using a Hitachi S-3400N microscope and transmission electron microscopy (TEM) using a JEOL-2000 FXII microscope equipped with a LaB6 gun.

X-Ray diffraction (XRD) patterns of the materials were recorded using a Bruker AXS D8 Advance diffractometer with a $\theta-\theta$ configuration and using $\mathrm{Cu} \mathrm{K} \alpha$ radiation $(\lambda$ $=0.15406 \mathrm{~nm})$. The graphite interlayer spacing $\left(d_{002}\right)$ was obtained from the position of the (002) peak applying the Bragg's equation and the crystallite sizes $\left(L_{c}\right)$ were calculated from Scherrer's equation on the (002) peak [66].

$\mathrm{N}_{2}$ adsorption-desorption isotherms of carbons were measured at $77 \mathrm{~K}$ using a Micromeritics ASAP 2020. The total surface area $\left(S_{B E T}\right)$ was calculated from BET equation and the total pore volume $\left(V_{T}\right)$ was determined using the single point method at $\mathrm{P} / \mathrm{P}_{0}=0.99$. The mesopore volume $\left(V_{\text {meso }}\right)$ was obtained from the analysis of the desorption branch of the $\mathrm{N}_{2}$ isotherm using the $\mathrm{BJH}$ method. The real density (or bulk density) $\left(\rho_{b}\right)$ of nanostructured carbons was determined by helium pycnometry at $30{ }^{\circ} \mathrm{C}$ using a Micromeritics AccuPyc II 1340 pycnometer.

Temperature programmed desorption (TPD) experiments were carried out in an AutoChem II 2920 apparatus to study the surface chemistry of carbon materials. The profiles of desorbed $\mathrm{CO}$ and $\mathrm{CO}_{2}$ were obtained in a quartz reactor heated under a constant flow of $\operatorname{Ar}\left(50 \mathrm{mLmin}^{-1}\right)$ at a heating rate of $10{ }^{\circ} \mathrm{C} \mathrm{min}^{-1}$ up to $1000{ }^{\circ} \mathrm{C}$. The amounts of $\mathrm{CO}$ and $\mathrm{CO}_{2}$ desorbed from the carbon samples were analyzed online by mass spectroscopy. The total amount of $\mathrm{CO}$ and $\mathrm{CO}_{2}$ released was calculated by integrating the area under the flow rate versus time curve. 
X-ray photoelectron spectroscopy (XPS) analyses were carried out with an ESCAPlus OMICRON system equipped with a hemispherical electron energy analyser operating at $150 \mathrm{~W}$, using a $\mathrm{MgK} \alpha \mathrm{X}$-ray source $(\mathrm{hv}=1253.6 \mathrm{eV})$ [65]. Survey scans were recorded from 0 to $1000 \mathrm{eV}$ at $0.5 \mathrm{eV}$ step, $0.2 \mathrm{~s}$ dwell and $50 \mathrm{eV}$ pass energy. $\mathrm{C} 1 \mathrm{~s}$ and $\mathrm{O} 1 \mathrm{~s}$ scans were obtained at $0.1 \mathrm{eV}$ step, $0.5 \mathrm{~s}$ dwell and $20 \mathrm{eV}$ pass energy. For calibration purposes, the $\mathrm{C}$ 1s binding energy of the graphitic peak (BE) was referenced at $284.6 \mathrm{eV}$. The CASA XPS data processing software allowed smoothing, Shirley type background subtraction, peak fitting and quantification.

Elemental analysis (EA) of carbon materials were performed in a CHNS-O Analyzer Thermo FlashEA 1112.

\subsection{Electronic conductivity measurement}

The experimental setup for the determination of the apparent electrical conductivity $(\sigma)$ of carbon powders consists of a thick-walled PVC cylinder (inner diameter $=8 \mathrm{~mm}$, length $=60 \mathrm{~mm}$ ) in which the sample is housed and closed between two steel plungers. The upper plunger compresses the sample at pressures from 0.5 to 140 $\mathrm{MPa}$, monitored by a calibrated pressure sensor. The experimental setup has been described in more detail in $[33,40]$.

The height of the carbon powder $(h)$ at each applied pressure was measured with a digital micrometer (Mitutoyo; accuracy $= \pm 0.02 \mathrm{~mm}$ ). The apparent density $(\rho)$ of the sample was determined from the weight and the volume occupied by the pressed powder in the cylinder. The starting apparent density $\left(\rho_{p}\right)$ corresponds to the non-compacted state. Initially, $1 \mathrm{~cm}^{3}$ of sample was placed into the cylinder in each run.

$\sigma$ was calculated from the corresponding resistance of the compressed powder $(R)$ at room temperature by a four-probe technique. $R$ was obtained from the adjustment of voltage and current slope, which are set by applying known values of potential (current 
up to $20 \mathrm{~mA}$ ) with an Array 3645A power supply, and registering the voltage drop in the sample and calibrated resistors with a $6 \frac{1}{2}$ digits Array M3500A multimeter. $\sigma$ was then determined from $\mathrm{R}$ by using the following equation (Eq. 1):

$$
\sigma=\frac{h}{R \cdot A}
$$

Eq. 1

where $h$ and $A$ are the height and the cross-sectional area of the compressed samples at each applied pressure. The system contribution to the total resistance (about $80 \mathrm{~m} \Omega$ ) was determined before each experiment with the empty system and it was subtracted from the total experimental resistance.

To note that $\sigma$ values are given at different applied pressures. Thus, the apparent electrical conductivity depends on the carbon compaction degree. Carbon materials with different morphology and textural features are studied in this work, which may result in a different apparent density (or a different compaction degree) at a given pressure. In order to address this issue, intrinsic $\left(\sigma_{i}\right)$ electrical conductivities of carbons were calculated according to the percolation theory and the so-called general effective media (GEM) approximation (assuming that the air phase conductivity is zero) [33, 49]. Further details of the determination of intrinsic conductivities are given later (section 3.2).

\section{Results}

\subsection{Physicochemical characterization of nanostructured carbon materials}

The morphology of nanostructured carbon powders was studied by SEM and TEM (see Fig. 1). The commercial carbon Vulcan consists of an aggregation of spherical nanoparticles which are composed of random aligned crystallites (Fig. 1a). On the other hand, CNF present a nanofilament morphology with well-aligned graphitic layers as can be in Fig. $1 \mathrm{~b}$ for $\mathrm{CNF}-\mathrm{O}_{\mathrm{m}}$. SEM images of $\mathrm{CNC}$ evidenced the spherical morphology of this material, which is opened forming graphitic carbon curved ribbons (Fig. 1c for CNC$\mathrm{O}_{\mathrm{m}}$ ). SEM and TEM characterization also confirmed that the metal was (at least partially) 
removed from $\mathrm{CNF}$ and $\mathrm{CNC}$ matrixes by the $\mathrm{HNO}_{3}$ treatments. Indeed, the surface metal content of carbons obtained by XPS decreased substantially after oxidation (see Others XPS in Table 2). However, oxidation treatments did not affect the morphological properties of Vulcan, CNF and CNC (see Fig. S1, Supporting Information). Finally, OMC showed an ordered honeycomb structure consisting of carbon nanorods with uniform mesopores (Fig. 1d). After OMC graphitization, the resulting material (OMC-g) preserved partially their ordered structure (Fig. S1).

The structure of carbon materials was studied by XRD. All carbons presented a peak around $2 \theta=25^{\circ}$ which is associated with the graphite (002) diffraction line, with the exception of OMC (Fig. S2 in the Supporting Information). Table 1 reports the XRD parameters obtained from the (002) peak. Crystallite sizes, and hence, the crystalline character of carbons increases following the sequence: OMC-g $<$ Vulcan $<\mathrm{CNC}<\mathrm{CNF}$. These differences are explained by the structure of carbons. CNF and CNC evidenced larger $L_{c}$ values (10.3 and $8.0 \mathrm{~nm}$, respectively) due to their graphitic structure originated by the regular alienation of graphene layers. On the other hand, Vulcan exhibited a lower crystal size $(1.7 \mathrm{~nm})$, which is explained by the crystallites present in the amorphous carbon primary particles. Interestingly, oxidation treatments did not affect substantially the graphitic character of Vulcan, $\mathrm{CNF}$ and $\mathrm{CNC}$ since similar $d_{002}$ and $L_{c}$ values were obtained after oxidation with $\mathrm{HNO}_{3}$. Finally, the mesoporous material OMC did not present diffraction due to its amorphous nature. After graphitization, the resulting material (OMC-g) showed a slight diffraction at $25^{\circ}\left(L_{c}=1.3 \mathrm{~nm}\right)$ due to an increase of the crystallinity character during the heat treatment at $1500^{\circ} \mathrm{C}$. 
Table 1. XRD parameters of carbon materials obtained from the graphite (002) peak.

\begin{tabular}{lcccc}
\hline Sample & $2 \theta\left(^{\circ}\right)$ & $F W H M\left(^{\circ}\right)$ & $d_{002}(\AA)$ & $L_{c}(\mathrm{~nm})$ \\
\hline Vulcan & 25.01 & 4.82 & 3.559 & 1.7 \\
Vulcan-O & 25.05 & 4.79 & 3.552 & 1.7 \\
\hline CNF & 26.56 & 0.79 & 3.353 & 10.3 \\
CNF-O $_{\mathbf{m}}$ & 26.54 & 0.78 & 3.356 & 10.5 \\
CNF-O $_{\text {s }}$ & 26.55 & 0.72 & 3.355 & 11.3 \\
\hline CNC & 26.30 & 1.01 & 3.386 & 8.0 \\
CNC-O & 26.23 & 0.97 & 3.394 & 8.4 \\
\hline OMC & - & - & - & - \\
OMC-g & 24.75 & 6.10 & 3.595 & 1.3 \\
\hline
\end{tabular}

The surface chemistry of carbon materials was studied by TPD. The profiles of desorbed $\mathrm{CO}$ and $\mathrm{CO}_{2}$ can be found in Fig. S3, while Table 2 reports the amount ( $\mu$ mol $\mathrm{g}^{-1}$ ) of oxygen functional groups released as $\mathrm{CO}$ and $\mathrm{CO}_{2}$. The total oxygen amount was determined by TPD $\left(O_{T P D}\right)$ and EA $\left(O_{E A}\right)$ (Table 2). Similar results were obtained by both techniques indicating that the volatile matter of carbons correlate with the amounts of released $\mathrm{CO}$ and $\mathrm{CO}_{2}$. However, $\mathrm{OMC}$ presented an $\mathrm{O}_{\text {TPD }}$ amount of 4.8 wt. \%, while around 2 times more $(8.4 \mathrm{wt} . \%)$ was measured from EA, which is attributed to surface groups in interior sites which are not desorbed at $1000^{\circ} \mathrm{C}$ due to pore diffusion restrictions [65].

$\mathrm{HNO}_{3}$ treatments led to the introduction of oxygenated species on the carbon samples (see Table 2). However, in the case of $\mathrm{CNC}$, a lower oxygen amount was obtained after oxidation, which is explained by the removal of metal oxides from the graphitization precursor salt (Co and $\mathrm{Ni})$ and mesoporous generator $(\mathrm{Si})$ [65]. On the other hand, oxygen-containing functional groups were almost completely removed during the graphitization of OMC.

The surface oxygen amount was also obtained by XPS $\left(O_{X P S}\right)$. XPS survey spectra can be found in Fig. S4 in the Supporting Information. Higher oxygen contents were determined by XPS for all the carbons in comparison to those obtained by TPD or EA 
due to an oxygen enrichment at the carbon surface. XPS was also used to quantify the atomic composition of the nanostructured carbon samples. Three components were deconvoluted by Gaussian/Lorentzian (40:60) fitting from XPS C1s high-resolution spectra $[69,70]: \mathrm{sp}^{2}$ graphitic carbon $(\mathrm{C}=\mathrm{C})$ and $\mathrm{sp}^{3}$ hybridized carbon $(\mathrm{C}-\mathrm{C})$ were combined in an asymmetric peak at $284.5 \mathrm{eV}$ [71], C-O bonds in hydroxyls $(\mathrm{C}-\mathrm{OH})$ or epoxides $(\mathrm{C}-\mathrm{O}-\mathrm{C})$ at $286.1-286.8 \mathrm{eV}$, and $\mathrm{C}=\mathrm{O}$ bonds in carbonyls $(\mathrm{C}=\mathrm{O})$ or carboxyl $(\mathrm{O}=\mathrm{C}-\mathrm{OH})$ at $288.1-289.0 \mathrm{eV}$. An additional peak at $290.9 \mathrm{eV}$ attributed to the $\pi-\pi^{*}$ shake up satellite contribution was found in all samples. The atomic compositions calculated from the survey as well as the deconvoluted XPS C1s spectra analysis are summarized in Table S1.

Table 2. Bulk and surface chemistry measured by TPD, EA and XPS of carbon materials.

\begin{tabular}{|c|c|c|c|c|c|c|c|c|}
\hline Sample & $\begin{array}{c}C O \\
\left.(\mu \mathrm{mol} \mathrm{g})^{-1}\right)\end{array}$ & $\begin{array}{c}\mathrm{CO}_{2} \\
\left.(\mu \mathrm{mol} \mathrm{g})^{-1}\right)\end{array}$ & $\begin{array}{c}O_{T P D} \\
(w t . \%)\end{array}$ & $\begin{array}{c}O_{E A} \\
(w t . \%)\end{array}$ & $\begin{array}{c}O_{X P S} \\
(w t . \%)\end{array}$ & $\begin{array}{c}C_{X P S} \\
\text { (at. \%) }\end{array}$ & $\begin{array}{c}O_{X P S} \\
(\text { at. } \%)\end{array}$ & $\begin{array}{l}\text { OthersXPS } \\
(\text { at. } \%)^{a}\end{array}$ \\
\hline Vulcan & 174 & 106 & 0.6 & 0.4 & 2.8 & 97.9 & 2.1 & 0.0 \\
\hline Vulcan-O & 1603 & 957 & 5.6 & 7.0 & 12.5 & 90.3 & 9.7 & 0.0 \\
\hline CNF & 245 & 80 & 0.6 & 0.5 & 3.1 & 97.3 & 2.4 & 0.3 \\
\hline $\mathrm{CNF}-\mathrm{O}_{\mathrm{m}}$ & 320 & 71 & 0.7 & 1.2 & 4.8 & 96.3 & 3.7 & 0.0 \\
\hline $\mathrm{CNF}-\mathrm{O}_{\mathrm{s}}$ & 704 & 645 & 3.2 & 2.0 & 6.9 & 94.8 & 5.2 & 0.0 \\
\hline$\overline{\mathrm{CNC}}$ & 1139 & 356 & 3.0 & 3.5 & 11.3 & 83.3 & 10.2 & 6.4 \\
\hline $\mathrm{CNC}^{-\mathrm{O}_{\mathrm{m}}}$ & 2602 & 832 & 6.8 & 6.8 & 10.7 & 89.3 & 8.5 & 2.2 \\
\hline OMC & 1475 & 770 & 4.8 & 8.4 & 11.2 & 91.4 & 8.6 & 0.0 \\
\hline OMC-g & -- & -- & 0.1 & 0.2 & 0.7 & 99.5 & 0.5 & 0.0 \\
\hline
\end{tabular}
$\mathrm{a}=\mathrm{Ni}$ and $\mathrm{Al}$ in $\mathrm{CNF} ; \mathrm{Ni}, \mathrm{Co}$ and $\mathrm{Si}$ in $\mathrm{CNC}$ and $\mathrm{CNC}-\mathrm{O}_{\mathrm{m}}$.

The materials present different textural properties. Table 3 summarizes the calculations obtained from $\mathrm{N}_{2}$ physisorption. Comparing the results of the untreated carbon materials, OMC presented the highest adsorption capacity $\left(S_{B E T}=812 \mathrm{~m}^{2} \mathrm{~g}^{-1}, V_{T}\right.$ $\left.=0.55 \mathrm{~cm}^{3} \mathrm{~g}^{-1}\right)$ although with the lowest mesopore fraction $(57 \%$ in terms of pore volume). In contrast, CNF evidenced the lowest surface area $\left(70 \mathrm{~m}^{2} \mathrm{~g}^{-1}\right)$ with a developed mesoporosity (98\%). Vulcan and CNC presented intermediate $S_{B E T}\left(238\right.$ and $306 \mathrm{~m}^{2} \mathrm{~g}^{-1}$, respectively) and mesopore contents ( 83 and $61 \%$, respectively). 
After oxidation treatments, textural properties presented a different behavior depending on the carbon material. A decrease of the specific surface area was evidenced for Vulcan and CNC, which might be partially explained by a slight modification of the original bulk morphology during the oxidation [67]. On the other hand, a slight increase of the surface area and pore volume was observed after CNF oxidation with nitric acid due to a combination of the growth catalyst removal and roughening of the outer surface of the nanofilaments [40]. With respect to the effect of graphitization of OMC on textural properties, a decrease of the surface area and the pore volume was evidenced associated to a removal of the microporosity by the surface annealing during the high temperature treatment.

Table 3 reports also the grain density $\left(\rho_{g}\right)$ calculated from the real density $\left(\rho_{b}\right)$ obtained by He pycnometry and the $V_{T}$ from $\mathrm{N}_{2}$ physisorption according to Eq. 2 [49]:

$$
\rho_{g}=\frac{1}{V_{T^{+}} \frac{1}{\rho_{b}}}
$$

$\mathrm{CNF}$ and CNC presented lower pore volumes in comparison to Vulcan and OMC, and consequently, the former materials are denser, as showed by the higher values of the grain density (as observed initially for the non-compacted state density, $\rho_{p}$ ). After oxidation with nitric acid, the $\rho_{g}$ was preserved in the case of Vulcan, while a slight decrease was evidenced for CNF and CNC. In contrast, a larger grain density was obtained after graphitization of OMC from $0.84 \mathrm{~g} \mathrm{~cm}^{-3}$ for the original material to $1.18 \mathrm{~g} \mathrm{~cm}^{-3}$ for OMCg. 
Table 3. Textural properties of carbon nanomaterials derived from $\mathrm{N}_{2}$ physisorption and He pycnometry analyses.

\begin{tabular}{lccccccc}
\hline Sample & $\begin{array}{c}S_{B E T} \\
\left(\mathrm{~m}^{2} \mathrm{~g}^{-1}\right)^{\mathrm{a}}\end{array}$ & $\begin{array}{c}V_{T} \\
\left(\mathrm{~cm}^{3} \mathrm{~g}^{-1}\right)\end{array}$ & $\begin{array}{c}V_{\text {meso }} \\
\left(\mathrm{cm}^{3} \mathrm{~g}^{-1}\right)\end{array}$ & $\begin{array}{c}V_{\text {meso }} \\
(\%)^{\mathrm{b}}\end{array}$ & $\begin{array}{c}\rho_{b} \\
\left(\mathrm{~g} \mathrm{~cm}^{-3}\right)^{\mathrm{c}}\end{array}$ & $\begin{array}{c}\rho_{g} \\
\left(\mathrm{~g} \mathrm{~cm}^{-3}\right)\end{array}$ & $\begin{array}{c}\rho_{p} \\
\left(\mathrm{~g} \mathrm{~cm}^{-3}\right)^{\mathrm{d}}\end{array}$ \\
\hline Vulcan & 238 & 0.38 & 0.31 & 83 & 1.95 & 1.12 & 0.27 \\
Vulcan-O & 181 & 0.38 & 0.33 & 86 & 1.95 & 1.12 & 0.37 \\
\hline CNF & 70 & 0.23 & 0.23 & 98 & 2.29 & 1.50 & 0.57 \\
CNF-O $_{\mathbf{m}}$ & 76 & 0.24 & 0.24 & 98 & 2.18 & 1.43 & 0.58 \\
CNF-O $_{\mathbf{s}}$ & 78 & 0.25 & 0.24 & 97 & 2.19 & 1.42 & 0.58 \\
\hline CNC & 306 & 0.19 & 0.12 & 61 & 2.28 & 1.59 & 0.86 \\
CNC-O $_{\mathbf{m}}$ & 234 & 0.17 & 0.13 & 78 & 1.90 & 1.44 & 0.65 \\
\hline OMC & 812 & 0.55 & 0.31 & 57 & 1.57 & 0.84 & 0.33 \\
OMC-g & 417 & 0.34 & 0.27 & 82 & 1.96 & 1.18 & 0.27 \\
\hline
\end{tabular}

$\mathrm{a}=$ BET equation applied to $\mathrm{N}_{2}$ isotherms. $\mathrm{b}=$ mesopore fraction in terms of pore volume. $\mathrm{c}=\mathrm{He}$ pycnometry. $\mathrm{d}=$ Non-compacted state.

\subsection{Electrical conductivity of nanostructured carbon materials}

It is known that the electrical conductivity measurement of a bulk powder results in a lower value than that of its isolated particles; likewise, the apparent electrical conductivity of a powder increases as it is compacted due to a greater contact between its components: crystals, particles and grains [33, 49, 72]. The apparent electrical conductivity of different carbonaceous powders was measured at different degrees of compaction as can be seen in Fig. 2. In all cases, the apparent electrical conductivity increases with the applied pressure as a result of an apparent density rise. As-synthetized carbon nanomaterials showed different apparent electrical conductivities, increasing in the order: $\mathrm{OMC}<\mathrm{CNC}<\mathrm{CNF}<$ Vulcan. Although Vulcan and CNF present apparent electrical conductivities of the same order of magnitude, CNC exhibit values 10 times lower, and up to $10^{4}-10^{5}$ times lower in the case of OMC (Fig. 2b). These differences may be related to the different structure of carbon nanomaterials: the amorphous carbon OMC evidenced the lowest electrical conductivity, while an improved conductivity was obtained for samples with well-aligned graphitic layers, CNF and CNC. In spite of the intermediate structure of Vulcan (it is formed by an aggregation of amorphous primary 
particles, which consist of graphitic crystallites), it presented the highest apparent electrical conductivity.

Regarding the oxidation treatments, most samples show a remarkable loss of electrical apparent conductivity. This decrease is more evident depending on the severity of the treatment: treatments with nitric acid at $120^{\circ} \mathrm{C}\left(\mathrm{O}_{\mathrm{s}}\right)$ reduce the apparent electrical conductivity more than $50 \%$, as can be see for Vulcan and CNF, while mild treatments at room temperature $\left(\mathrm{O}_{\mathrm{m}}\right)$ evidenced a lower decrease. In particular, a reduction of the electrical conductivity around 5-20\% (depending on the applied pressure) is observed in the case of CNF or even a slight increase for CNC. However, this increase is explained by a modification in the apparent density of $\mathrm{CNC}$, as will be explained later. Oxidation hinders the electronic movement in the powder particles as a result of the disruption of the graphene $\mathrm{sp}^{2}$-carbon network in graphite stack-based materials by oxygen-containing functionalities. This has already been proven in bulk conductivity measurements of CNF under different oxidation degrees [40]. Conversely, the graphitization treatment of OMC, which initially present a very low conductivity, led to a surprising increase of the electrical apparent, with values similar to Vulcan. In this case, the high temperature treatment favours both the formation of $\mathrm{sp}^{2}$-carbon domains and the oxygen functional groups removal improving the electrical conductivity.

However, differences of the apparent electrical conductivity might be attributed to a different degree of compaction. At a given pressure, each carbon powder shows a different apparent density which is related with its inherent porosity, as shown in Fig. 3. In this context, the large difference in the surface area and pore volume of carbon materials (see Table 3) result in a different packing density, influencing the macroscopic conductivity of the carbon during powder compression. CNC and CNF exhibited initial apparent densities higher than Vulcan and OMC (Fig. 3). The low apparent density (or 
high porosity) of the OMC might partially explain its low electrical conductivity. In either case, both oxidation and graphitization result in a reduction in apparent density, except for CNF, which showed no significant differences.

Based on the above, there seems to be a synergistic effect of the inherent crystallinity degree and the compaction of each sample in the resulting electrical conductivity. In Fig. 4 the electrical apparent conductivity is related with comparable solid (Fig. 4a-b) and grain (Fig. 4c-d) volume fractions, $\Phi$ and $\Phi_{g}$, respectively, which correspond to the volume occupied by the solid and the grains (the porosity is included) with respect to the volume occupied by the powder at a defined pressure. Despite the great differences concerning the morphology, structure and textural properties of carbon powders, the use of these volume fractions allows a direct comparison of their electrical conductivity. The calculation of solid and grain volume fractions can be found in $[33,49]$. According to the GEM approximation to describe the electrical conductivity of a powder $[33,49]$, the intrinsic and the grain electrical conductivities of a compacted carbon material, $\sigma_{i}$ and $\sigma_{g}$, respectively, can be described by Eq. 3 and Eq. 4:

$$
\begin{gathered}
\sigma=\sigma_{i}\left(\frac{\Phi-\Phi_{c}}{1-\Phi_{c}}\right)^{t} \\
\sigma=\sigma_{g}\left(\frac{\Phi_{g}-\Phi_{c, g}}{1-\Phi_{c, g}}\right)^{t}
\end{gathered}
$$

Here, $\Phi_{c}$ and $\Phi_{c, g}$ correspond the threshold volume fractions of solid and grains, respectively. These parameters are related to the minimum value of $\Phi$ or $\Phi_{g}$ that forms a connected path between the conducting solid or the grains, respectively. $\Phi_{c}$ is also socalled as percolation threshold or critical volume fraction [49]. $t$ is an exponent that depends on the critical volume fractions and the shape of the grains [49]. The models described by Eq. 3 and Eq. 4 and the experimental data are represented in Fig. 4. In addition, the calculated parameters obtained from the fitting of the experimental values 
are collected in Table $4 . \Phi_{c}$ and $\Phi_{c, g}$ have been estimated by the extrapolation of the curves of Fig. 4 to a conductivity of zero $[33,55]$. As expected, calculated values of $\sigma_{i}$ are higher than the values of $\sigma_{g}$ due to the non-conductive contribution of the porosity of the grains in the last case. $\sigma_{i}$ represents the theoretic electrical conductivity of the carbon materials when the entire volume is occupied by the solid. The calculation of the $\sigma_{g}$ in this work responds to the need to provide theoretical values of conductivity (closer to reality) of a powder system formed by the particle entanglement. Carbon materials show intrinsic electrical conductivities from 1.5 to 3.3 times greater than grain conductivities, being this effect less remarkable for carbons with a lower total pore volume as in the case of CNF and CNC sample sets. Indeed, contacts between nanofibers or nanocoils represent $35-50 \%$ of the total resistive contribution $\left(\left(\sigma_{i^{-}} \sigma_{g}\right) / \sigma_{i}\right)$ in a grain (see Fig. S5). In the same way, this resistivity is higher in Vulcan (60\%) and OMC (47-69\%). Leaving aside the effect of the material porosity or the interparticle contact effect, it can be seen that the intrinsic conductivity of the carbon powders studied in this work varies from 855 to $9523 \mathrm{~S} \mathrm{~m}^{-1}$ (within the range of previously reported carbonaceous powders [33, 49, 57]) with the exception of the very low conductivity exhibited by the amorphous-nature OMC $\left(0.033 \mathrm{~S} \mathrm{~m}^{-1}\right)$.

On the other hand, differences in electrical conductivity are more evident if we compare the structure or oxygen content in samples. Thereby, oxygenation treatments or graphitization in the case of $\mathrm{OMC}$, had a remarkable influence on the intrinsic or grain electrical conductivities, highlighting the conductivity increase exhibited by OMC after graphitization (OMC-g), which corresponds with the higher intrinsic electrical conductivity measured in this study $\left(9523 \mathrm{~S} \mathrm{~m}^{-1}\right)$. In addition, graphite crystals (which are presented in all the carbon structures with the exception of OMC, see Table 1) have a clear influence on the electrical conductivity of carbon powders. After oxidation 
treatments higher crystal sizes $\left(L_{c}\right)$ and higher interlayer spacings $\left(d_{002}\right)$ were obtained due to the oxygenated group intercalation, which led to an electrical conductivity decrease. In agreement with these results, Vulcan and OMC-g with a low size of the graphite crystals (1.7 and $1.3 \mathrm{~nm}$, respectively) exhibited the highest intrinsic electrical conductivity.

Table 4. Intrinsic electrical conductivities and fitting parameters calculated from the apparent electrical conductivity curves.

\begin{tabular}{|c|c|c|c|c|c|}
\hline Sample & $\Phi_{c, g}$ & $\sigma_{g}\left(\mathbf{S ~ m}^{-1}\right)$ & $t$ & $\Phi_{c}$ & $\sigma_{i}\left(\mathbf{S ~ m}^{-1}\right)$ \\
\hline Vulcan & 0.20 & 2822 & 1.46 & 0.11 & 7324 \\
\hline Vulcan-O & 0.33 & 1318 & 1.23 & 0.19 & 3279 \\
\hline CNF & 0.34 & 1967 & 0.96 & 0.22 & 3449 \\
\hline $\mathrm{CNF}-\mathrm{O}_{\mathrm{m}}$ & 0.37 & 1645 & 0.92 & 0.24 & 2856 \\
\hline $\mathrm{CNF}-\mathrm{O}_{\mathrm{s}}$ & 0.39 & 966 & 0.95 & 0.25 & 1779 \\
\hline CNC & 0.52 & 561 & 1.09 & 0.36 & 1132 \\
\hline $\mathrm{CNC}-\mathrm{O}_{\mathrm{m}}$ & 0.43 & 559 & 0.94 & 0.33 & 855 \\
\hline OMC & 0.38 & 0.033 & 1.36 & 0.20 & 0.109 \\
\hline OMC-g & 0.21 & 5055 & 1.03 & 0.13 & 9523 \\
\hline
\end{tabular}

Finally, the oxygen content showed also a clear role on the electrical conductivity of carbon powders. Indeed, the electrical conductivity exhibited an exponential decrease with both the bulk oxygen content (measured by TPD and EA) and the surface oxygen (measured by XPS) for all the carbon powders studied in this work, regardless of their different origin and graphitic structure (see Fig. S6). Briefly, oxygen fundamentally disrupts the graphene $\mathrm{sp}^{2}$ network that makes up each graphite stack in the form of both basal functional groups as epoxides or phenols and edge functional groups such as carboxylic acids or carbonyls $[69,73]$. This alteration in the atomic scale alters the passage of the electronic current in the first instance with the destruction of the cloud of delocalized electrons that form the conductive $\pi$ orbitals on the graphene plane. The involvement of the latter in electrical conductivity of a specific carbon material has 
already been proven in some works [55], and it is clearly showed here considering the $\pi-\pi^{*}$ transition component in the deconvoluted C1s region of the XPS spectra (Table S1). Therefore, there is a direct relationship between the surface oxygen content and the electrical conductivity of a carbon powder even for samples of such different nature as those presented in this work. In fact, both intrinsic and grain electrical conductivities fall exponentially as the oxygen content increases (as can be seen in Fig. 5).

This fact can be also verified considering the different types of carbon nanomaterials, where the oxidation or graphitization treatments imply a modification in the oxygen content and therefore in the electrical conductivity. Oxidation treatments led to the creation of oxygen-containing functionalities on the carbon surface which led to a decrease of the conductivity. Note that in the case of CNC, an electrical conductivity loss is also obtained after the oxidation process $\left(\mathrm{CNC}-\mathrm{O}_{\mathrm{m}}\right)$, however the oxygen content is lower due to the removal of oxides of $\mathrm{Co}, \mathrm{Ni}$ and $\mathrm{Si}$ [65]. In addition, it is important to highlight the high electrical conductivities offered by Vulcan both before and after its oxidation, which could be related to the low size of the graphite crystals $(1.7 \mathrm{~nm})$ and its outstanding textural properties already commented. In contrast, the heat treatment at 1500 ${ }^{\circ} \mathrm{C}$ of OMC resulted in a clear removal of the oxygen content and the graphitization of the carbon (with crystals of $1.3 \mathrm{~nm}$ ), and thus a great increase of the electrical conductivity (the highest of the materials studied in this work).

\section{Conclusions}

This work reports a study of the electrical conductivity of powders of nanostructured carbons with different structural, morphological and textural properties: a commercial carbon black (Vulcan XC-72R) and synthesized OMC, CNF and CNC. Additionally, carbons were subjected to chemical oxidation treatments or graphitization to study the effect of the oxygen content and the structural properties on the electrical 
conductivity.

The apparent electrical conductivity was calculated from the sample resistance measurement under compaction using the four-probe technique. The apparent electrical conductivity of a powder increases as it is compressed due to a greater contact between its components: crystals, particles and grains. However, differences in the physicochemical properties of carbons led to a different apparent density at a given pressure, which hinders a direct comparison of apparent electrical conductivities. In order to address this issue, the intrinsic and grain electrical conductivities of carbon powders were determined according to the percolation theory and the GEM approximation. Carbons presented an intrinsic electrical conductivity in the range from 855 to $9523 \mathrm{~S} \mathrm{~m}^{-}$ ${ }^{1}$ with the exception of the very low value exhibited by the amorphous-nature OMC $(0.033$ $\left.\mathrm{S} \mathrm{m}^{-1}\right)$. Oxidation treatments resulted in the generation of oxygen species at carbon surfaces, which disrupt the graphene $\mathrm{sp}^{2}$ network, decreasing the electrical conductivity. In contrast, the high temperature treatment in inert atmosphere of OMC resulted in a surprising increase of its electrical conductivity due to the oxygen removal and the carbon graphitization. Interestingly, Vulcan and graphitized OMC presented the highest conductivities (with intrinsic values of 7324 and $9523 \mathrm{~S} \mathrm{~m}^{-1}$, respectively), which seems to be related to the low size of their graphite crystals $(1.7 \mathrm{~nm}$ and $1.3 \mathrm{~nm}$, respectively).

Additionally, a correlation between the intrinsic and grain electrical conductivities and the surface oxygen amount was stated among the different carbon materials. Despite of the different nature of carbon powders, an exponential decrease of the electrical conductivity with the oxygen amount was evidenced.

This study provides a useful and comparative overview of the effect of oxygen amount and structural properties of the electrical conductivity of nanostructured carbon powders, which could guide researchers in the field of nanocomposites to better 
understand the behaviour of these carbons as fillers.

\section{Acknowledgments}

The authors gratefully acknowledge financial support given by Spanish MINECO (ENE2014-52158-C2-1-R). Furthermore, the authors wish to thank Dra. Ana Beatriz García (INCAR-CSIC) for the graphitization treatment of OMC and the TPD measurements. 


\section{References}

[1] Rajesh, T. Ahuja, D. Kumar, Recent progress in the development of nano-structured conducting polymers/nanocomposites for sensor applications, Sensors and Actuators B: Chemical, 136 (2009) 275286.

[2] G.A. Snook, P. Kao, A.S. Best, Conducting-polymer-based supercapacitor devices and electrodes, Journal of Power Sources, 196 (2011) 1-12.

[3] S.K. Bhattacharya, A.C.D. Chaklader, Review on Metal-Filled Plastics. Part1. Electrical Conductivity, Polymer-Plastics Technology and Engineering, 19 (1982) 21-51.

[4] C. Klason, D.H. Mcqueen, J. Kubát, Electrical properties of filled polymers and some examples of their applications, Macromolecular Symposia, 108 (1996) 247-260.

[5] W. Zhang, A.A. Dehghani-Sanij, R.S. Blackburn, Carbon based conductive polymer composites, J Mater Sci 42 (2007) 3408-3418.

[6] N. Grossiord, J. Loos, O. Regev, C.E. Koning, Toolbox for Dispersing Carbon Nanotubes into Polymers To Get Conductive Nanocomposites, Chemistry of Materials, 18 (2006) 1089-1099.

[7] S. Kim, T.-H. Le, C.S. Park, G. Park, K.H. Kim, S. Kim, O.S. Kwon, G.T. Lim, H. Yoon, A SolutionProcessable, Nanostructured, and Conductive Graphene/Polyaniline Hybrid Coating for Metal-Corrosion Protection and Monitoring, Scientific Reports, 7 (2017) 15184.

[8] N. Xu, Q. Zhang, H. Yang, Y. Xia, Y. Jiang, In-situ preparation of hierarchical flower-like TiO2/carbon nanostructures as fillers for polymer composites with enhanced dielectric properties, Scientific Reports, 7 (2017) 43970.

[9] Y.J. Noh, H.-I. Joh, J. Yu, S.H. Hwang, S. Lee, C.H. Lee, S.Y. Kim, J.R. Youn, Ultra-high dispersion of graphene in polymer composite via solvent free fabrication and functionalization, Scientific Reports, 5 (2015) 9141.

[10] S. Stassi, G. Canavese, V. Cauda, S.L. Marasso, C.F. Pirri, Evaluation of different conductive nanostructured particles as filler in smart piezoresistive composites, Nanoscale Research Letters, 7 (2012) 327.

[11] S. Ghosh, T. Maiyalagan, R.N. Basu, Nanostructured conducting polymers for energy applications: towards a sustainable platform, Nanoscale, 8 (2016) 6921-6947.

[12] F. Zhao, Y. Shi, L. Pan, G. Yu, Multifunctional Nanostructured Conductive Polymer Gels: Synthesis, Properties, and Applications, Accounts of Chemical Research, 50 (2017) 1734-1743.

[13] J. Sandler, M.S.P. Shaffer, T. Prasse, W. Bauhofer, K. Schulte, A.H. Windle, Development of a dispersion process for carbon nanotubes in an epoxy matrix and the resulting electrical properties, Polymer, 40 (1999) 5967-5971.

[14] M. Sumita, K. Sakata, S. Asai, K. Miyasaka, H. Nakagawa, Dispersion of fillers and the electrical conductivity of polymer blends filled with carbon black, Polymer Bulletin, 25 (1991) 265-271.

[15] J.C. Huang, Carbon black filled conducting polymers and polymer blends, Advances in Polymer Technology, 21 (2002) 299-313.

[16] E.K. Sichel, J.I. Gittleman, P.J. Sheng, Electrical properties of carbon-polymer composites, Journal of Electronic Materials, 11 (1982) 699-747.

[17] R. Sengupta, M. Bhattacharya, S. Bandyopadhyay, A.K. Bhowmick, A review on the mechanical and electrical properties of graphite and modified graphite reinforced polymer composites, Progress in Polymer Science, 36 (2011) 638-670.

[18] F. Carmona, P. Prudhon, F. Barreau, Percolation in short fibres epoxy resin composites: Conductivity behavior and finite size effects near threshold, Solid State Communications, 51 (1984) 255-257.

[19] M.H. Al-Saleh, U. Sundararaj, A review of vapor grown carbon nanofiber/polymer conductive composites, Carbon, 47 (2009) 2-22.

[20] I. Suelves, R. Utrilla, D. Torres, S. de Llobet, J.L. Pinilla, M.J. Lázaro, R. Moliner, Preparation of polymer composites using nanostructured carbon produced at large scale by catalytic decomposition of methane, Materials Chemistry and Physics, 137 (2013) 859-865.

[21] U. Tayfun, Y. Kanbur, U. Abaci, H.Y. Guney, E. Bayramli, Mechanical, flow and electrical properties of thermoplastic polyurethane/fullerene composites: Effect of surface modification of fullerene, Composites Part B: Engineering, 80 (2015) 101-107.

[22] I. Sapurina, M. Mokeev, V. Lavrentev, V. Zgonnik, M. Trchová, D.r. Hlavatá, J. Stejskal, Polyaniline complex with fullerene C60, European Polymer Journal, 36 (2000) 2321-2326.

[23] S. Stankovich, D.A. Dikin, G.H.B. Dommett, K.M. Kohlhaas, E.J. Zimney, E.A. Stach, R.D. Piner, S.T. Nguyen, R.S. Ruoff, Graphene-based composite materials, Nature, 442 (2006) 282. 
[24] F.H. Gojny, M.H.G. Wichmann, B. Fiedler, I.A. Kinloch, W. Bauhofer, A.H. Windle, K. Schulte, Evaluation and identification of electrical and thermal conduction mechanisms in carbon nanotube/epoxy composites, Polymer, 47 (2006) 2036-2045.

[25] J.K.W. Sandler, J.E. Kirk, I.A. Kinloch, M.S.P. Shaffer, A.H. Windle, Ultra-low electrical percolation threshold in carbon-nanotube-epoxy composites, Polymer, 44 (2003) 5893-5899.

[26] M.F.L. De Volder, S.H. Tawfick, R.H. Baughman, A.J. Hart, Carbon Nanotubes: Present and Future Commercial Applications, Science, 339 (2013) 535-539.

[27] T. Kuilla, S. Bhadra, D. Yao, N.H. Kim, S. Bose, J.H. Lee, Recent advances in graphene based polymer composites, Progress in Polymer Science, 35 (2010) 1350-1375.

[28] A.H. Castro Neto, F. Guinea, N.M.R. Peres, K.S. Novoselov, A.K. Geim, The electronic properties of graphene, Reviews of Modern Physics, 81 (2009) 109-162.

[29] A.K. Geim, K.S. Novoselov, The rise of graphene, Nature Materials, 6 (2007) 183.

[30] K.S. Novoselov, A.K. Geim, S.V. Morozov, D. Jiang, Y. Zhang, S.V. Dubonos, I.V. Grigorieva, A.A. Firsov, Electric Field Effect in Atomically Thin Carbon Films, Science, 306 (2004) 666-669.

[31] J. Moser, A. Barreiro, A. Bachtold, Current-induced cleaning of graphene, Applied Physics Letters, 91 (2007) 163513.

[32] Z. Yao, C. Dekker, P. Avouris, Electrical Transport Through Single-Wall Carbon Nanotubes, In: Dresselhaus M.S., Dresselhaus G., Avouris P. (eds) Carbon Nanotubes. Topics in Applied Physics, vol 80. Springer, Berlin, Heidelberg2001.

[33] D. Sebastián, A.G. Ruiz, I. Suelves, R. Moliner, M.J. Lázaro, On the importance of the structure in the electrical conductivity of fishbone carbon nanofibers, Journal of Materials Science, 48 (2013) 1423-1435. [34] H. Dai, E.W. Wong, C.M. Lieber, Probing Electrical Transport in Nanomaterials: Conductivity of Individual Carbon Nanotubes, Science, 272 (1996) 523-526.

[35] T.W. Ebbesen, H.J. Lezec, H. Hiura, J.W. Bennett, H.F. Ghaemi, T. Thio, Electrical conductivity of individual carbon nanotubes, Nature, 382 (1996) 54.

[36] K. Kaneto, M. Tsuruta, G. Sakai, W.Y. Cho, Y. Ando, Electrical conductivities of multi-wall carbon nano tubes, Synthetic Metals, 103 (1999) 2543-2546.

[37] B.Q. Wei, R. Vajtai, P.M. Ajayan, Reliability and current carrying capacity of carbon nanotubes, Applied Physics Letters, 79 (2001) 1172-1174.

[38] H.J. Li, W.G. Lu, J.J. Li, X.D. Bai, C.Z. Gu, Multichannel Ballistic Transport in Multiwall Carbon Nanotubes, Physical Review Letters, 95 (2005) 086601.

[39] S.J. Tans, M.H. Devoret, H. Dai, A. Thess, R.E. Smalley, L.J. Geerligs, C. Dekker, Individual singlewall carbon nanotubes as quantum wires, Nature, 386 (1997) 474.

[40] D. Sebastián, I. Suelves, R. Moliner, M.J. Lázaro, The effect of the functionalization of carbon nanofibers on their electronic conductivity, Carbon, 48 (2010) 4421-4431.

[41] B. Marinho, M. Ghislandi, E. Tkalya, C.E. Koning, G. de With, Electrical conductivity of compacts of graphene, multi-wall carbon nanotubes, carbon black, and graphite powder, Powder Technology, 221 (2012) 351-358.

[42] M. Ghislandi, E. Tkalya, B. Marinho, C.E. Koning, G. de With, Electrical conductivities of carbon powder nanofillers and their latex-based polymer composites, Composites Part A: Applied Science and Manufacturing, 53 (2013) 145-151.

[43] A. Rani, S. Nam, K.A. Oh, M. Park, Electrical Conductivity of Chemically Reduced Graphene Powders under Compression, Carbon letters, 2 (2010) 90-95.

[44] Z.K. Tang, L. Zhang, N. Wang, X.X. Zhang, G.H. Wen, G.D. Li, J.N. Wang, C.T. Chan, P. Sheng, Superconductivity in 4 Angstrom Single-Walled Carbon Nanotubes, Science, 292 (2001) 2462-2465.

[45] J.-C. Charlier, X. Blase, S. Roche, Electronic and transport properties of nanotubes, Reviews of Modern Physics, 79 (2007) 677-732.

[46] M.S. Kim, N.M. Rodriguez, R.T.K. Baker, The role of interfacial phenomena in the structure of carbon deposits, Journal of Catalysis, 134 (1992) 253-268.

[47] Z.R. Ismagilov, A.E. Shalagina, O.Y. Podyacheva, A.V. Ischenko, L.S. Kibis, A.I. Boronin, Y.A. Chesalov, D.I. Kochubey, A.I. Romanenko, O.B. Anikeeva, T.I. Buryakov, E.N. Tkachev, Structure and electrical conductivity of nitrogen-doped carbon nanofibers, Carbon, 47 (2009) 1922-1929.

[48] S. Marinković, Č. Sužnjević, M. Djordjević, Pressure dependence of the electrical resistivity of graphite powder and its mixtures, physica status solidi (a), 4 (1971) 743-754.

[49] A. Celzard, J.F. Marêché, F. Payot, G. Furdin, Electrical conductivity of carbonaceous powders, Carbon, 40 (2002) 2801-2815.

[50] N. Deprez, D.S. McLachlan, The analysis of the electrical conductivity of graphite conductivity of graphite powders during compaction, Journal of Physics D: Applied Physics, 21 (1988) 101. 
[51] A. Espinola, P.M. Miguel, M.R. Salles, A.R. Pinto, Electrical properties of carbons-resistance of powder materials, Carbon, 24 (1986) 337-341.

[52] S. Rattanaweeranon, P. Limsuwan, V. Thongpool, V. Piriyawong, P. Asanithi, Influence of Bulk Graphite Density on Electrical Conductivity, Procedia Engineering, 32 (2012) 1100-1106.

[53] D. Pantea, H. Darmstadt, S. Kaliaguine, L. Sümmchen, C. Roy, Electrical conductivity of thermal carbon blacks: Influence of surface chemistry, Carbon, 39 (2001) 1147-1158.

[54] J. Sánchez-González, A. Macías-García, M.F. Alexandre-Franco, V. Gómez-Serrano, Electrical conductivity of carbon blacks under compression, Carbon, 43 (2005) 741-747.

[55] D. Pantea, H. Darmstadt, S. Kaliaguine, C. Roy, Electrical conductivity of conductive carbon blacks: influence of surface chemistry and topology, Applied Surface Science, 217 (2003) 181-193.

[56] V. Celorrio, D. Sebastián, L. Calvillo, A.B. García, D.J. Fermin, M.J. Lázaro, Influence of thermal treatments on the stability of Pd nanoparticles supported on graphitised ordered mesoporous carbons, International Journal of Hydrogen Energy, 41 (2016) 19570-19578.

[57] S. Stankovich, D.A. Dikin, R.D. Piner, K.A. Kohlhaas, A. Kleinhammes, Y. Jia, Y. Wu, S.T. Nguyen, R.S. Ruoff, Synthesis of graphene-based nanosheets via chemical reduction of exfoliated graphite oxide, Carbon, 45 (2007) 1558-1565.

[58] J.C. Charlier, J.P. Issi, Electrical conductivity of novel forms of carbon, Journal of Physics and Chemistry of Solids, 57 (1996) 957-965.

[59] K. Kinoshita, Carbon: electrochemical and physicochemical properties, 1988.

[60] Q. Liu, W. Ren, Z.-G. Chen, L. Yin, F. Li, H. Cong, H.-M. Cheng, Semiconducting properties of cupstacked carbon nanotubes, Carbon, 47 (2009) 731-736.

[61] V.L. Kuznetsov, Y.V. Butenko, A.L. Chuvilin, A.I. Romanenko, A.V. Okotrub, Electrical resistivity of graphitized ultra-disperse diamond and onion-like carbon, Chemical Physics Letters, 336 (2001) 397404.

[62] A.G. Pandolfo, A.F. Hollenkamp, Carbon properties and their role in supercapacitors, Journal of Power Sources, 157 (2006) 11-27.

[63] A. Nogales, G. Broza, Z. Roslaniec, K. Schulte, I. Šics, B.S. Hsiao, A. Sanz, M.C. García-Gutiérrez, D.R. Rueda, C. Domingo, T.A. Ezquerra, Low Percolation Threshold in Nanocomposites Based on Oxidized Single Wall Carbon Nanotubes and Poly(butylene terephthalate), Macromolecules, 37 (2004) 7669-7672.

[64] R. Rozada, J.I. Paredes, S. Villar-Rodil, A. Martínez-Alonso, J.M.D. Tascón, Towards full repair of defects in reduced graphene oxide films by two-step graphitization, Nano Research, 6 (2013) 216-233.

[65] S. Pérez-Rodríguez, D. Sebastián, M.J. Lázaro, E. Pastor, Stability and catalytic properties of nanostructured carbons in electrochemical environments, Journal of Catalysis, 355 (2017) 156-166.

[66] S. Pérez-Rodríguez, N. Rillo, M.J. Lázaro, E. Pastor, Pd catalysts supported onto nanostructured carbon materials for $\mathrm{CO}_{2}$ valorization by electrochemical reduction, Appl. Catal., B, 163 (2015) 83-95.

[67] S. Pérez-Rodríguez, E. Pastor, M.J. Lázaro, Electrochemical behavior of the carbon black Vulcan XC72R: Influence of the surface chemistry, International Journal of Hydrogen Energy, 43 (2018) 7911-7922. [68] S. Pérez-Rodríguez, G. García, M.J. Lázaro, E. Pastor, DEMS strategy for the determination of the difference in surface acidity of carbon materials, Electrochemistry Communications, 90 (2018) 87-90.

[69] D. Torres, P. Arcelus-Arrillaga, M. Millan, J. Pinilla, I. Suelves, Enhanced Reduction of Few-Layer Graphene Oxide via Supercritical Water Gasification of Glycerol, Nanomaterials, 7 (2017) 447.

[70] D. Torres, J.L. Pinilla, I. Suelves, Unzipping of multi-wall carbon nanotubes with different diameter distributions: Effect on few-layer graphene oxide obtention, Applied Surface Science, 424 (2017) 101-110. [71] H. Estrade-Szwarckopf, XPS photoemission in carbonaceous materials: A "defect" peak beside the graphitic asymmetric peak, Carbon, 42 (2004) 1713-1721.

[72] K.-J. Euler, The conductivity of compressed powders. A review, Journal of Power Sources, 3 (1978) 117-136.

[73] D. Torres, J.L. Pinilla, R. Moliner, I. Suelves, On the oxidation degree of few-layer graphene oxide sheets obtained from chemically oxidized multiwall carbon nanotubes, Carbon, 81 (2015) 405-417. 


\section{FIGURE CAPTIONS}

Fig. 1. SEM (left) and TEM (right) images of selected carbon materials: Vulcan (a), CNF$\mathrm{O}_{\mathrm{m}}(\mathrm{b}), \mathrm{CNC}-\mathrm{O}_{\mathrm{m}}(\mathrm{c})$ and $\mathrm{OMC}(\mathrm{d})$.

Fig. 2. Variation of apparent electrical conductivity with applied pressure.

Fig. 3. Variation of apparent density with the applied pressure.

Fig. 4. Electrical conductivities $(\sigma)$ of various carbonaceous powders as a function of their: a-b) solid $(\Phi)$; and c-d) grain volume fractions $\left(\Phi_{g}\right)$. The fitting curves are calculated from Eq. 3 and Eq. 4.

Fig. 5 a) Intrinsic and b) grain electrical conductivities versus surface atomic oxygen (measured by XPS). 
Figure 1
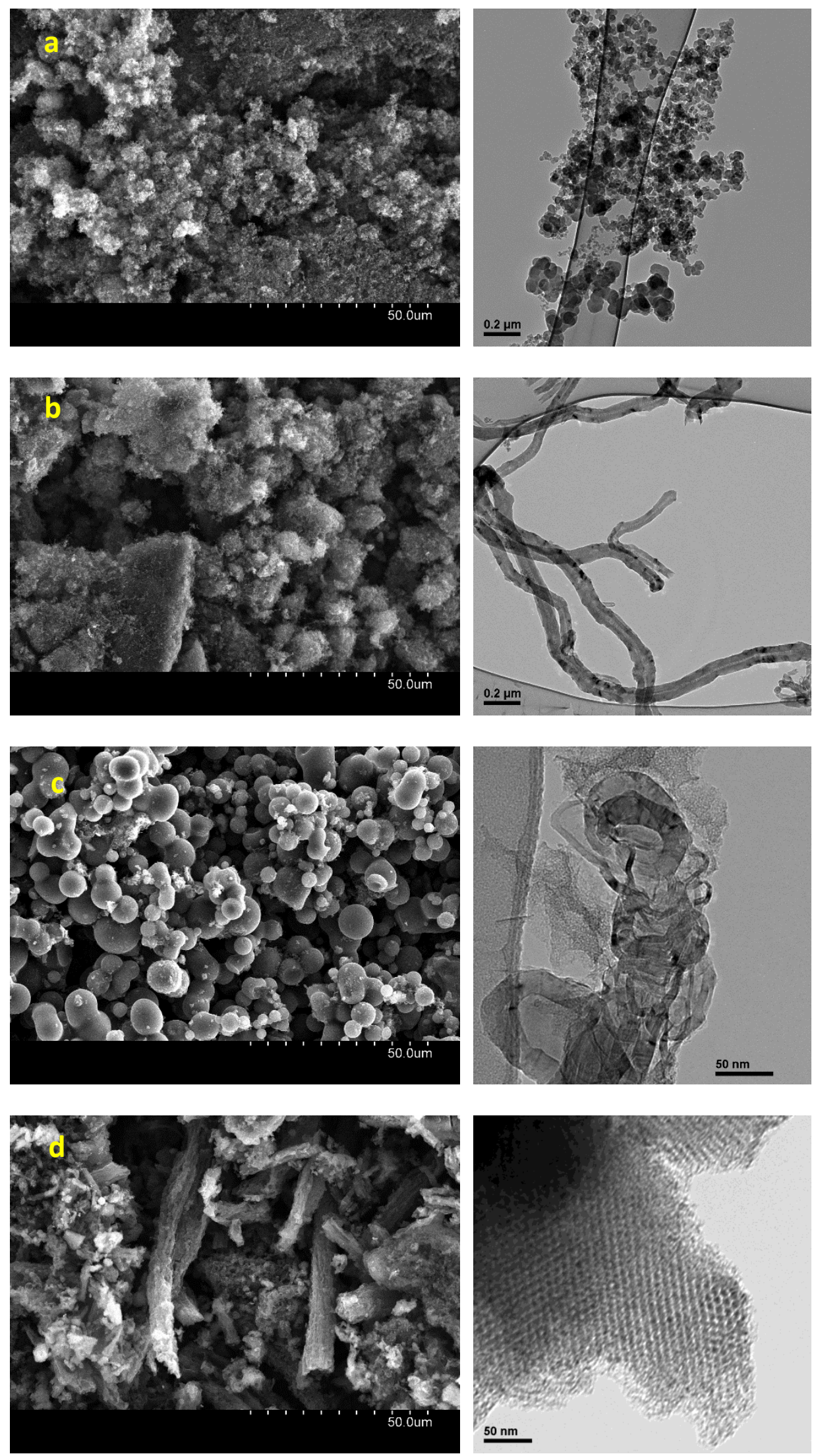


\section{Figure 2}
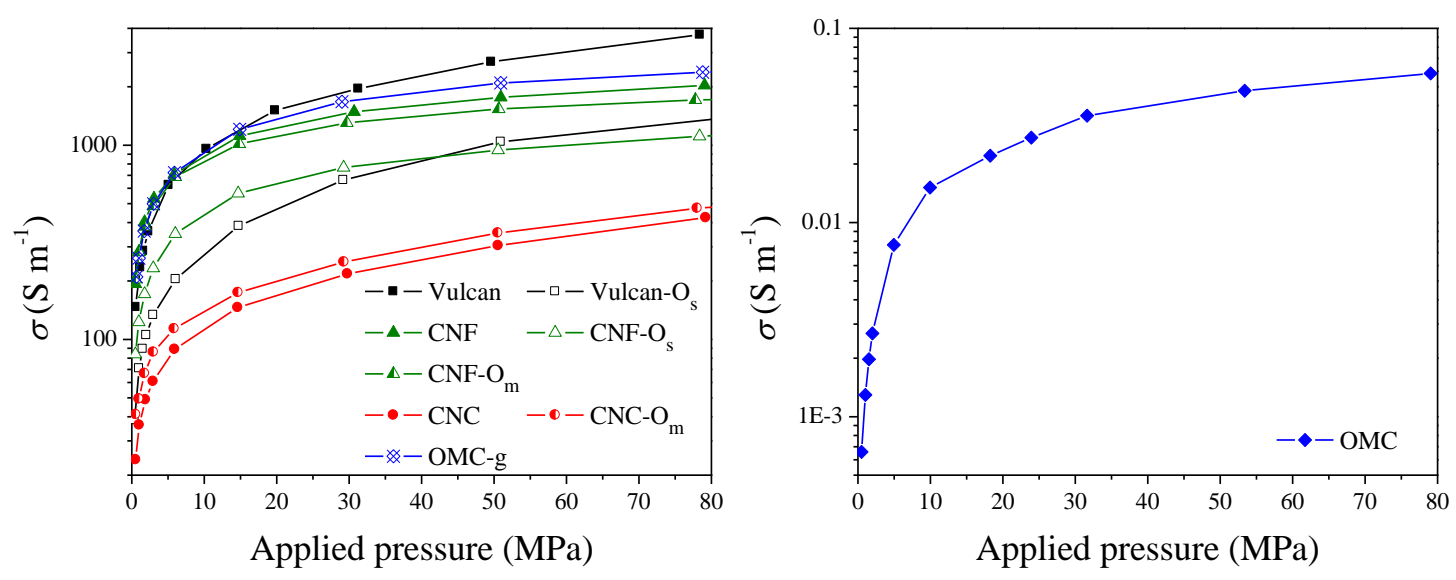


\section{Figure 3}

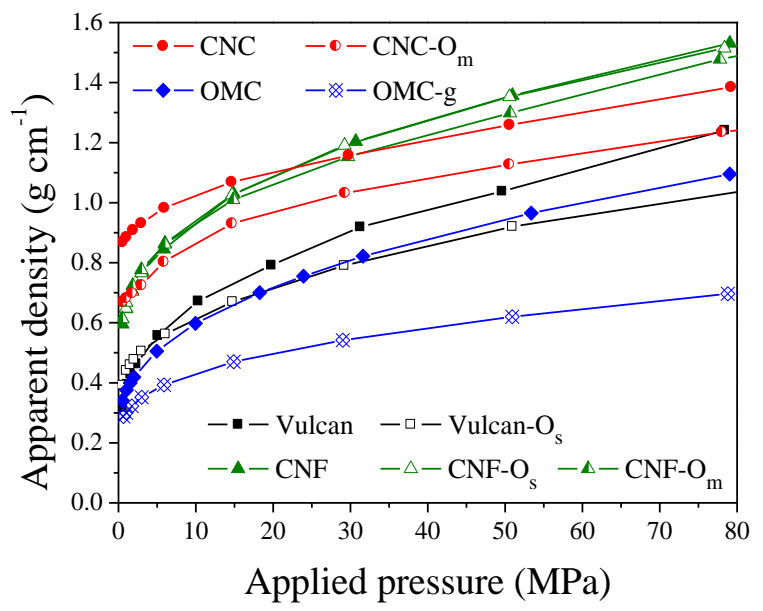


Figure 4
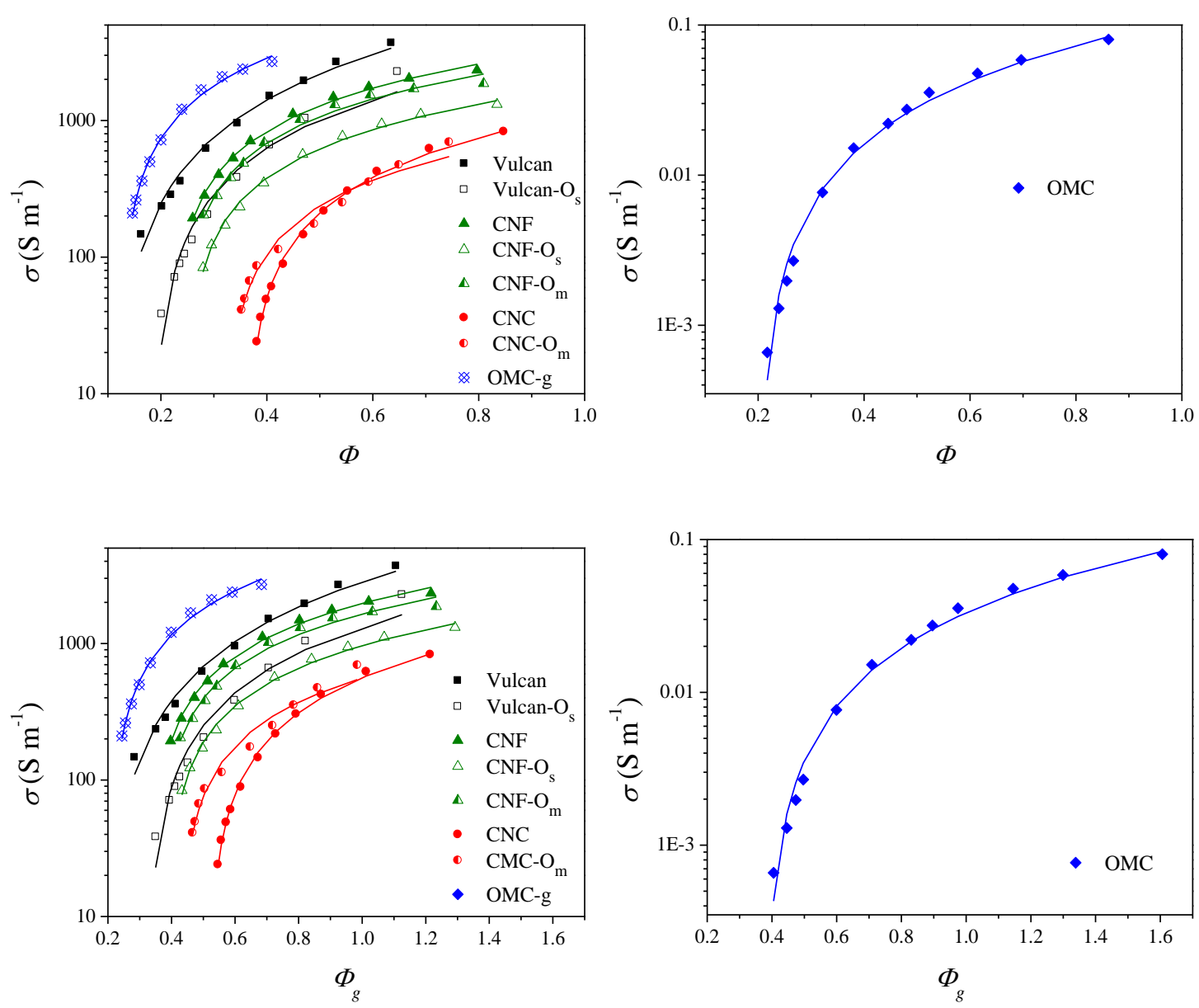


\section{Figure 5}
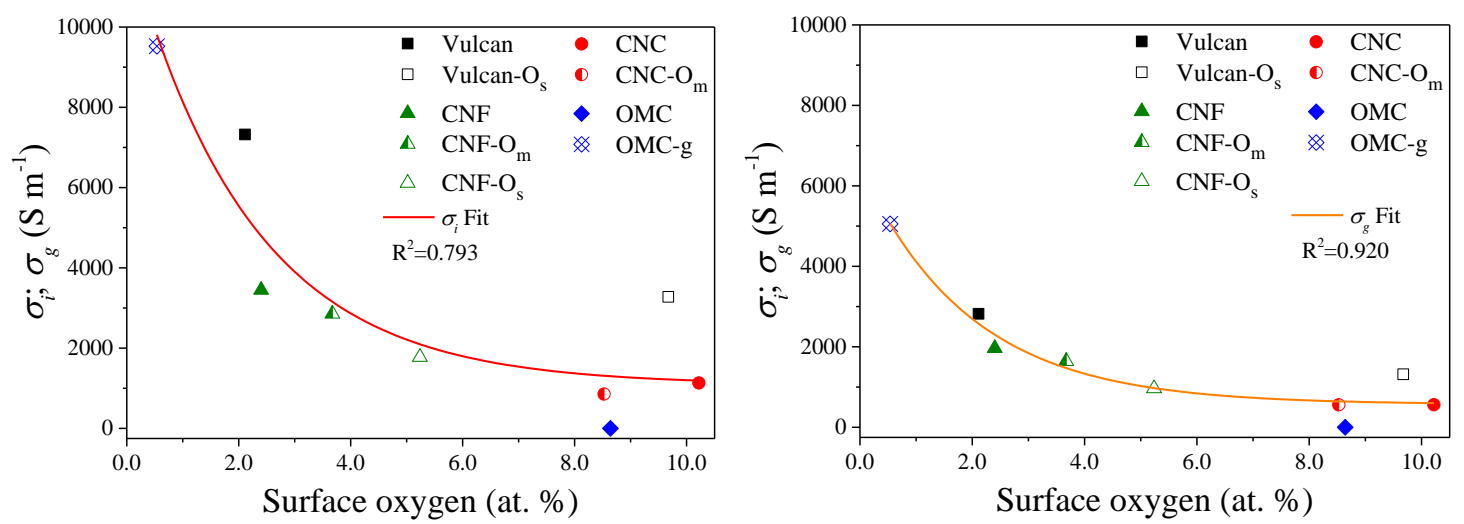